\title{
Article
}

\section{Spectroscopic and Structural Investigation of Multi-wall Carbon Nanotubes Functionalized by Sulfonated Poly(ether-ether-ketone) Chains}

\author{
Moulay-Rachid Babaa ${ }^{1,3^{*}}$, Alina Terechshenko ${ }^{2,3}$, Jean-Louis Bantignies ${ }^{4}$ and Zhumabay Bakenov ${ }^{2,3}$ \\ 1 College of Engineering, American University of the middle East, Egaila, Kuwait, mou- \\ lay.babaa@aum.edu.kw \\ 2 School of Engineering and Digital Sciences, Nazarbayev University, Institute of Batteries LLC, 53 Kabanbay \\ Batyr Avenue, Astana 010000, Kazakhstan, zbakenov@nu.edu.kz, alina.terechshenko@nu.edu.kz \\ 3 National Laboratory Astana, Nazarbayev University, Institute of Batteries LLC, 53 Kabanbay Batyr Avenue, \\ Astana 010000, Kazakhstan \\ 4 Laboratoire Charles Coulomb (L2C) UMR-CNRS 5221, Université de Montpellier, Place Eugène Bataillon - \\ CC069, F-34095 Montpellier Cedex 5- France, jean-louis.bantignies@umontpellier.fr \\ * Author to whom correspondence should be addressed. Moulay.babaa@aum.edu.kw
}

\begin{abstract}
Functionalization of multi-walled carbon nanotubes (MWNTs) surface with sulfonated poly(ether ether ketone) SPEEK chains using hexane diamine (HAD) as the interlinking molecule was investigated. MWNTs were first oxidized by nitric acid to generate carboxyl groups on their surface. Grafting of SPEEK chains on the MWNTs surface was achieved using hexane diamine as a cross-linking molecule. The attachment took place after the reaction of amine groups with carboxyl groups of oxidized MWNTs and sulfonate groups of SPEEK as confirmed by infrared (FTIR) analysis. Scanning electron microscopy (SEM) showed that MWNTs were packed into a dense and compact structure. Transmission electron microscopy (TEM) showed that the nanotubes were wrapped by polymer chains and arranged in a bundle like structure. These observations reveal that some of MWNTs were interconnected by SPEEK chains.
\end{abstract}

Keywords: Carbon nanotubes, Functionalization, Sulfonated Poly-Ether-Ether-Ketone, FTIR.

\section{Introduction}

Carbon nanotubes (CNTs) exhibit extraordinary mechanical $[1,2]$ and electronic properties [3,4]. Since their discovery in 1991, these materials have attracted strong interest in terms of their potential applications in various fields such as composites [5-7] and nano-electronics [8]. However, processing of CNTs presents many difficulties: they are insoluble in the common solvents and tend to exist as entangled agglomerates. Considerable research efforts have been focused on chemical modification of CNTs surface in order to improve their dispersibility in both organic and aqueous solvents by decreasing the van der Waals attractive forces between the nanotubes, and allow for a possibility to control the nature of binding between CNTs and adsorbed functional molecules [9]. Functionalization of CNTs gives a new approach to develop superior composite materials with high mechanical properties. It enables interactions between polymer matrix and CNTs to be controlled by using different functional groups attached to the nanotubes [10-12]. A noncovalent supramolecular approach which involves polymer wrapping of the nanotubes was shown to be promising for reinforcing the polymers and extending their applications in electronic devices [13, 14]. The covalent grafting of polymer chains onto CNTs is important because the long polymer chains help to improve the solubility of the tubes in a wide range of solvents even at a low degree of functionalization $[15,16]$ and lead to a strong interfacial bonding between the two components [17]. Many methodologies were applied for the covalent attachment of polymeric chains to the surface of CNTs [15]. Specifically, oxidation and fluorination are used to introduce respectively carboxylic and fluorine groups to the surfaces of the CNTs which allow the sidewall at- 
tachment of nucleophilic substituents carrying terminal functional groups. Diamines were widely and successfully used to connect the polymer chains to the oxidized or fluorinated CNTs [18- 20]. However, few studies report on the cross-linking of carbon nanotubes when diamines are used [21,22] and this effect needs to be further investigated. In this paper, we report on the covalent functionalization of multi-walled carbon nanotubes (MWNTs) with sulfonated poly (ether ether ketone) (SPEEK) chains using hexane diamine as an inter-linking molecule. Fourier transform infrared (FTIR) spectroscopy was used to give evidence of the covalent attachment of SPEEK to MWNTs, when SEM and TEM were used to characterize the morphological changes after the functionalization.

\section{Materials and Methods}

Multiwalled carbon nanotubes (MWNTs, CCVD method) were purchased from Nanocyl. The diameter distribution of MWNTs ranged from 4 to $15 \mathrm{~nm}$. Commercially available

Poly (ether ether ketone) (PEEK) was a Vitrex ${ }^{\circledR}$ PEEK 150 PF kindly provided by Victrex. All following materials were obtained from Aldrich and used as received: Dimethylformamide (DMF, 99\%), 1, 6-hexane diamine (HDA, 99\%),

$\mathrm{N}, \mathrm{N}^{\prime}$-dicyclohexylcarbodiimide (DCC, 99\%), sulphuric acid $\left(\mathrm{H}_{2} \mathrm{SO}_{4}, 98 \%\right)$ and nitric acid $\left(\mathrm{HNO}_{3}, 70 \%\right)$.

FTIR experiments were carried out on a Bruker IFS 66V spectrometer equipped with a N2-cooled MCT (Mercury Cadmium Telluride) detector. Transmission IR spectra were recorded in the 400-4000 $\mathrm{cm}^{-1}$ range. The spectral resolution was $2 \mathrm{~cm}^{-1}$ and 64 scans were co-added for each spectrum. Samples were ground thoroughly with potassium bromide $(\mathrm{KBr})$ at $1 \mathrm{wt} \%$ and the resulting powder was pressed into a transparent pellet using a hydraulic press.

The samples were analyzed using scanning electron microscopy (SEM) (FEI Quanta 200 FEG-SEM). Transmission electron microscopy TEM analyses were conducted on a $120 \mathrm{kV}$ JEOL 1200 EX II analytical electron microscope. The nanotubes were dispersed in absolute ethanol before preparing the grids for TEM imaging.

The synthesis of sulfonated PEEK (SPEEK) was carried out using $\mathrm{H}_{2} \mathrm{SO}_{4}$ treatment according to the literature data [23]. Typically, $20 \mathrm{~g}$ of PEEK was dried in a vacuum oven at $100{ }^{\circ} \mathrm{C}$ for 5 hours and then dissolved in $500 \mathrm{ml}$ of concentrated sulfuric acid $\left(\mathrm{H}_{2} \mathrm{SO}_{4}\right.$, $98 \%$ ) under vigorous stirring. The sulfonation degree (DS) of SPEEK in this paper was about $70 \%$. The DS was estimated by titration according to the technique described elsewhere [23]. Figure 1 shows a simplified scheme of the PEEK sulfonation.

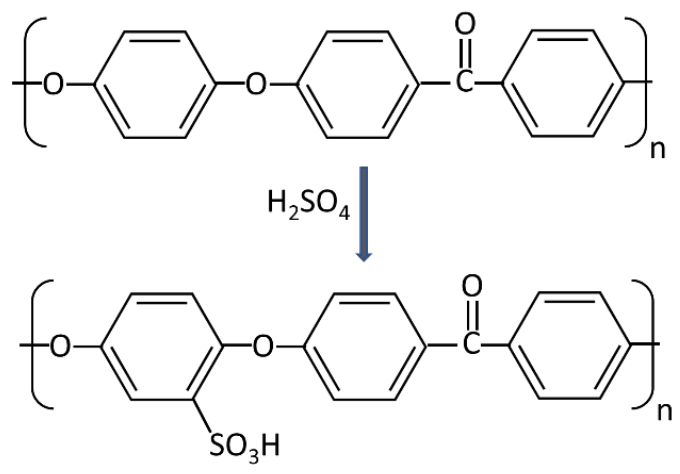

Figure 1. Schematic illustration of the sulfonation of PEEK.

Grafting reaction was carried out following the method reported elsewhere [24]. First, pristine MWNTs (P-MWCNTs, $50 \mathrm{mg}$ ) were oxidized using $\mathrm{HNO}_{3}$ treatment (250 
$\mathrm{ml}, 110^{\circ} \mathrm{C}, 2$ hours). Such treatment is known to eliminate metallic particles issued from the synthesis procedure but also to generate functional groups on the surface, particularly carboxylic acid groups. This treatment is known also to shorten the CNTs length. Further, the oxidized MWNTs (OX-MWNTs, $40 \mathrm{mg}$ ) were dispersed in DMF (200 ml) by ultrasonication for $2 \mathrm{~h}$. HAD (50 mg) and DCC (50 mg) were simultaneously added. The mixture was heated at $40{ }^{\circ} \mathrm{C}$ and stirred for $24 \mathrm{~h}$. After washing and filtration, functionalized MWNTs with HDA (HDA-MWNTs) was stored in the oven at $100{ }^{\circ} \mathrm{C}$ for 24 hours. Grafting reaction of SPEEK was carried out in the same conditions by dissolving $200 \mathrm{mg}$ of SPEEK and $50 \mathrm{mg}$ of HDA-MWNTs in $250 \mathrm{ml}$ of DMF $\left(40{ }^{\circ} \mathrm{C}\right.$,

$24 \mathrm{~h}$ ). The reaction took place between amine functions of HDA-MWNTs and sulfonate functions present in SPEEK. The sample was separated by filtering and washed by DMF several times to unsure the unreacted SPEEK chains were removed. The material was then dried in a vacuum oven at $100{ }^{\circ} \mathrm{C}$ for 24 hours and designated SPEEK-MWNTs. This material formed was brittle and hard to disperse and needed a sonication for 3 hours prior to TEM observation, which is significantly high compared to three other samples (40 minutes for both OX-MWNTs and HAD-MWNTs and 1 hour for P-MWNTs).

\section{Results}

The IR absorption spectra measured on MWCNT samples after each functionalization step are compared in Figures $2 \mathrm{a}$ and $2 \mathrm{~b}$. The IR spectra of HDA and DMF are also presented to ensure that all samples are free from any contamination. In the sample OX-MWNTs (spectrum noted (2)), a peak around $1720 \mathrm{~cm}^{-1}$ can be assigned to the stretching mode of the carbonyl vibrations $v(C=O)$ [25]. No such band can be seen in the spectra of the pristine MWNTs (noted (1)). The band centered at $1580 \mathrm{~cm}^{-1}$ is assigned to the tangential mode of the nanotubes [26]. This pick is more visible in oxidized MWNTs than in pristine nanotubes.

After the functionalization with HDA (sample (3)), IR spectrum shows a new band around $1498 \mathrm{~cm}^{-1}$ assigned to the stretching vibration of the C-N group.
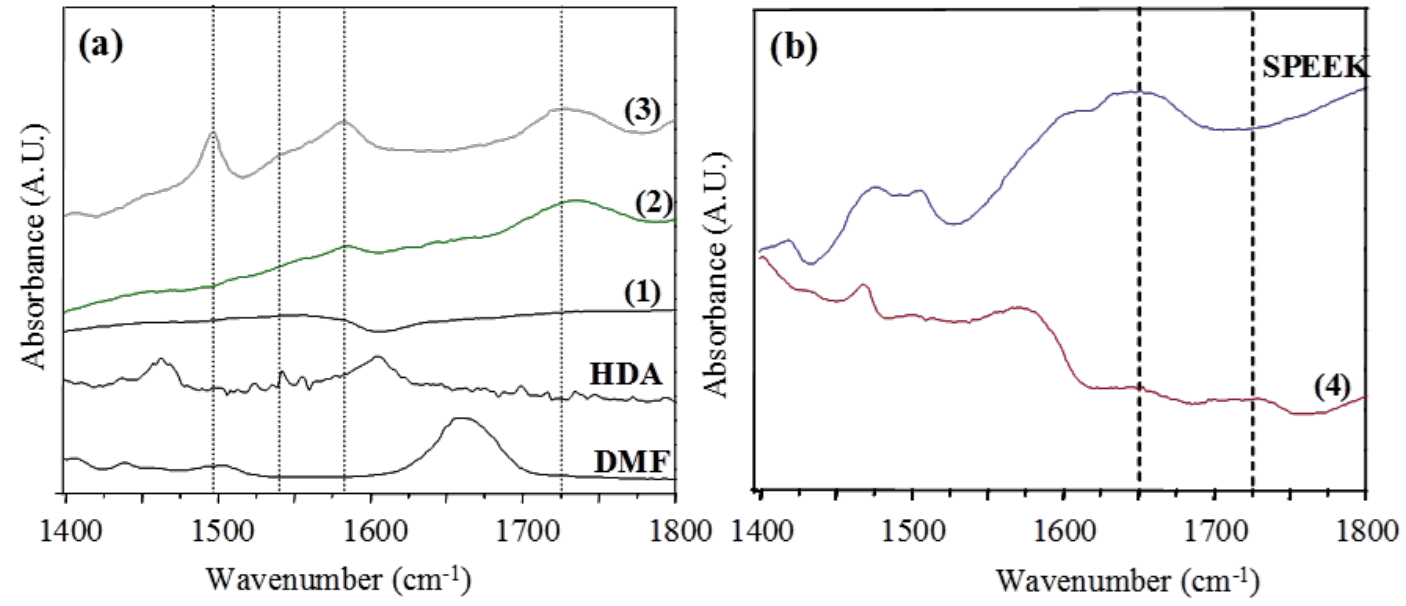

Figure 2. (a) IR spectra of (1) p-MWNTs, (2) OX-MWNTs, (3) HDA-MWNTs, HDA and DMF. (b) SPEEK and (4) SPEEK-MWNTs. 
The broad band around $1600 \mathrm{~cm}^{-1}$ in HDA is assigned to the coupling of $\mathrm{N}-\mathrm{H}$ group bending and the $\mathrm{C}-\mathrm{N}$ stretching vibration of the secondary amine group. The significant enhancement of the band around $1580 \mathrm{~cm}^{-1} \mathrm{can}$ be attributed to the overlapping of the IR active phonon mode of MWNTs and the N-H stretching mode of amide group. The IR spectra of SPEEK-MWNTs (Fig. 2b sample (4)) shows two peaks centered around 1650 and $1720 \mathrm{~cm}^{-1}$ both are attributed to the stretching mode of the carbonyl group vibrations. But compared to HDA-MWNTs sample, the second carbonyl peak at low frequency (1650 $\mathrm{cm}^{-1}$ ) is assigned to the ketone group of SPEEK.

Figure 3 shows the IR spectra the sulfones stretching region for SPEEK and SPEEK-MWNTs samples. The peak around $930 \mathrm{~cm}^{-1}$ corresponds to the stretching vibration of the S-O bond (single bond) in sulfonic acid groups and its disappearance was reported to be due to the dissociation of $-\mathrm{SO}_{3} \mathrm{H}$ groups in the case of perfluorosulfonated Nafion. [27]. After the grafting reaction (sample (4)), the spectrum shows a strong decrease of its intensity. This observation is in good agreement with the study referenced above.

The shoulder at $1016 \mathrm{~cm}^{-1}$ was reported to correspond to the symmetric stretching of S-O mode [28] and it can be clearly noticed that it disappears after the grafting reaction. Furthermore, Al Lafti [29] reported that the bending motion of carbonyl group appear at $1305 \mathrm{~cm}^{-1}$ in the case of PEEK and at $1320 \mathrm{~cm}^{-1}$ in SPEEK. Al Lafti also stated that this shift suggests a significant difference in structure of the diphenyl ether segments before and after sulfonation which imply that the sulfonation occurs preferably on the phenyl rings flanked with the two ether groups. In our case, a strong band centered at $1320 \mathrm{~cm}^{-1}$ is observed for SPEEK sample. After the grafting reaction, a strong reduction of its intensity combined with a shift to $1305 \mathrm{~cm}^{-1}$ is clearly noticed.

The band at $1024 \mathrm{~cm}^{-1}$ can be assigned to the stretching vibrations of $\mathrm{S}=\mathrm{O}$ group [29], while the two bands at 1082 and $1155 \mathrm{~cm}^{-1}$ are assigned to $v(\mathrm{O}=\mathrm{S}=\mathrm{O})$ symmetric [29] and asymmetric [30] stretching vibrations in sulfonic acid groups respectively. After the grafting reaction, a shift to lower wavenumbers can be noticed for the bands at $1024 \mathrm{~cm}^{-1}$ and $1082 \mathrm{~cm}^{-1}$. Yi et al., [30] have observed the same shift for the two frequencies in the case of poly(furfuryl alcohol) (PFA) grafted on sulfonated single-walled carbon nanotubes. They pointed out that this behavior is due to the electrostatic attractions between the sulfonic acid groups and the growing chain of PFA. Finally, two bands in the range of 1210- $1244 \mathrm{~cm}^{-1}$ appears in both samples. Previous studies [31-33] have suggested a doublet associated with the asymmetric stretching of sulfonate group with a second band located around $1200-1230 \mathrm{~cm}^{-1}$. The two bands may be associated with a second mode of asymmetric stretching of the $\mathrm{O}=\mathrm{S}=\mathrm{O}$ group. 


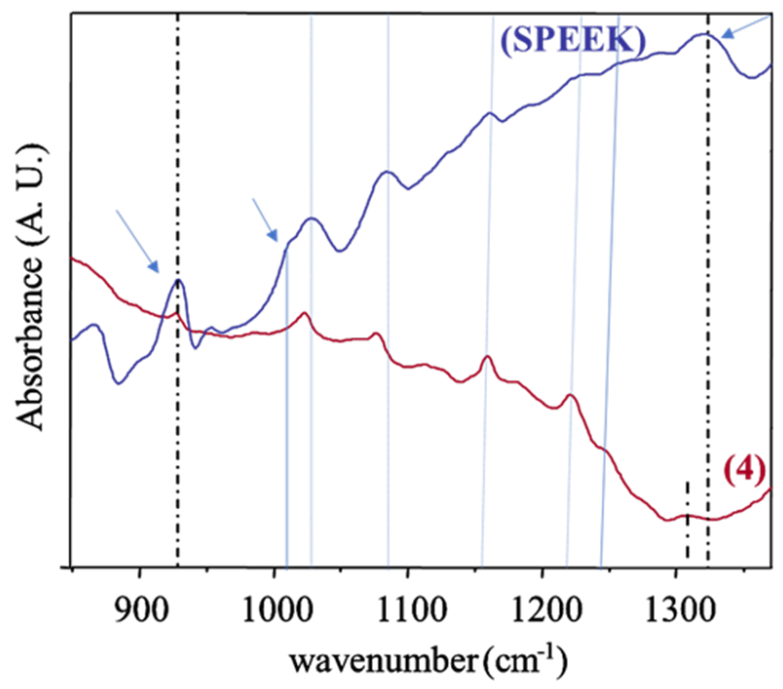

Figure 3. IR spectra of the sulfones stretching region for SPEEK and (4) SPEEK-MWNTs.

The structure of the samples before and after functionalization was observed using SEM and TEM. The pristine P-MWNTs exhibit a typical tubular structure and no impurities (amorphous carbon or metallic particles) were detected (Figure 4). It can be seen that the nanotube surface of MWNT is relatively smooth and clean and presents a loosely packed arrangement. The hollows are clearly evident in the TEM image. After the oxidative treatment (Figure 5), no significant change can be observed compared to the pristine sample. The tubes were not shortened after oxidation; however, TEM micrograph shows some defects on small diameter nanotubes surface as indicated by the arrows. SEM and TEM images of the sample after the grafting reaction of HAD (Figure 6) exhibit the same entangled structure and the tubes are randomly oriented. No evidence of tube-tube cross-linking structure can be observed.
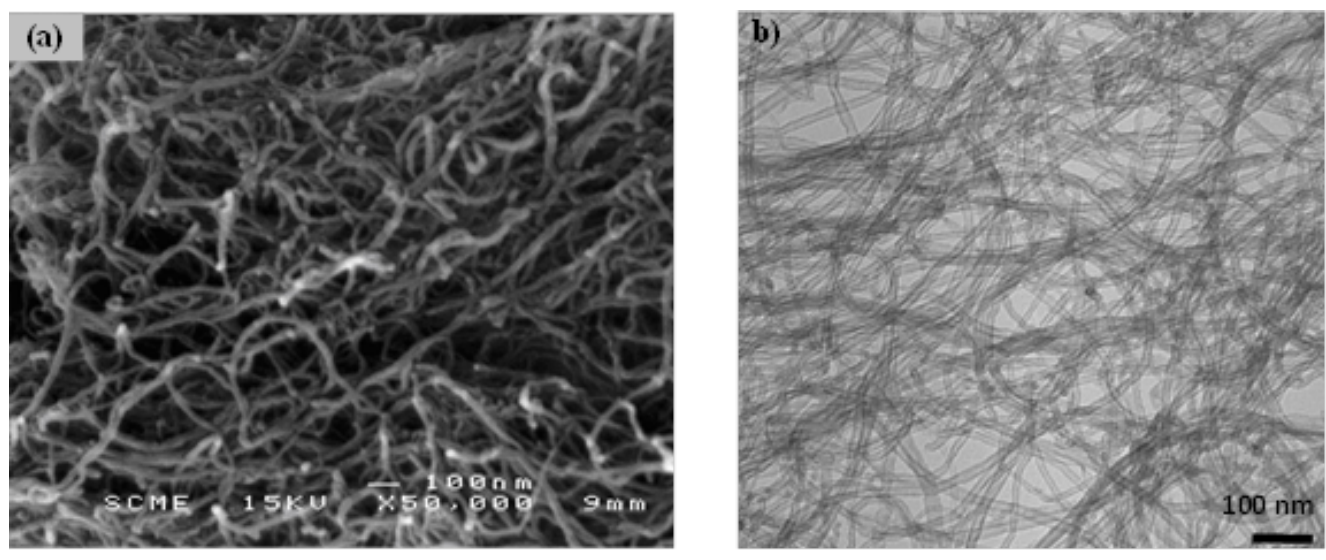

Figure 4. (a) SEM and (b) TEM micrographs of pristine MWNTs. 

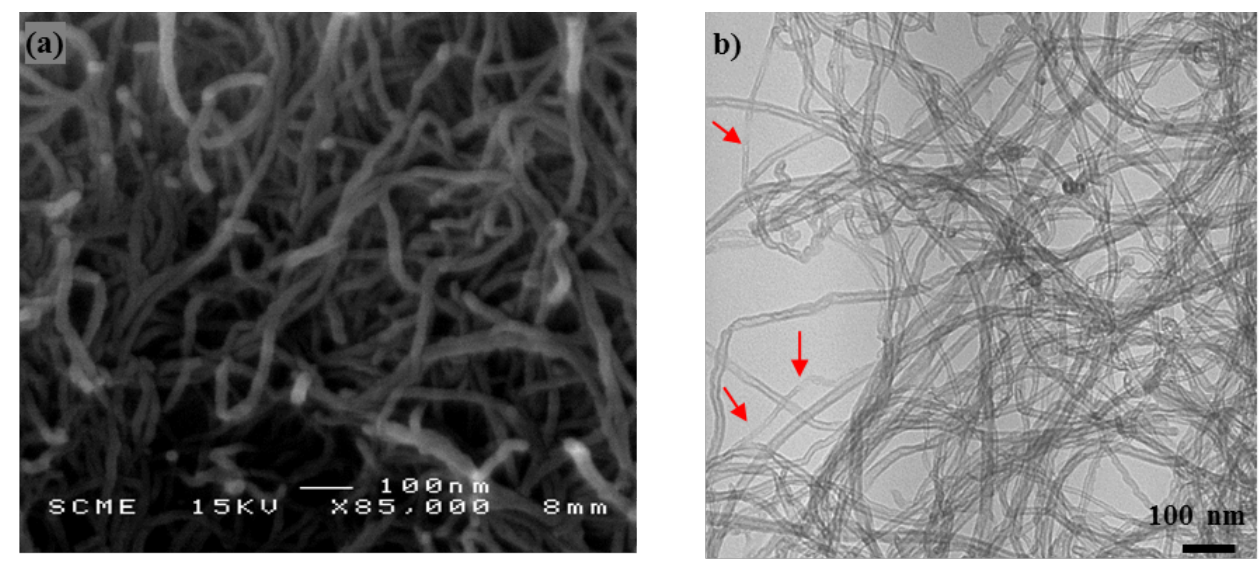

Figure 5. (a) SEM and (b) TEM micrographs of Ox-MWNTs.
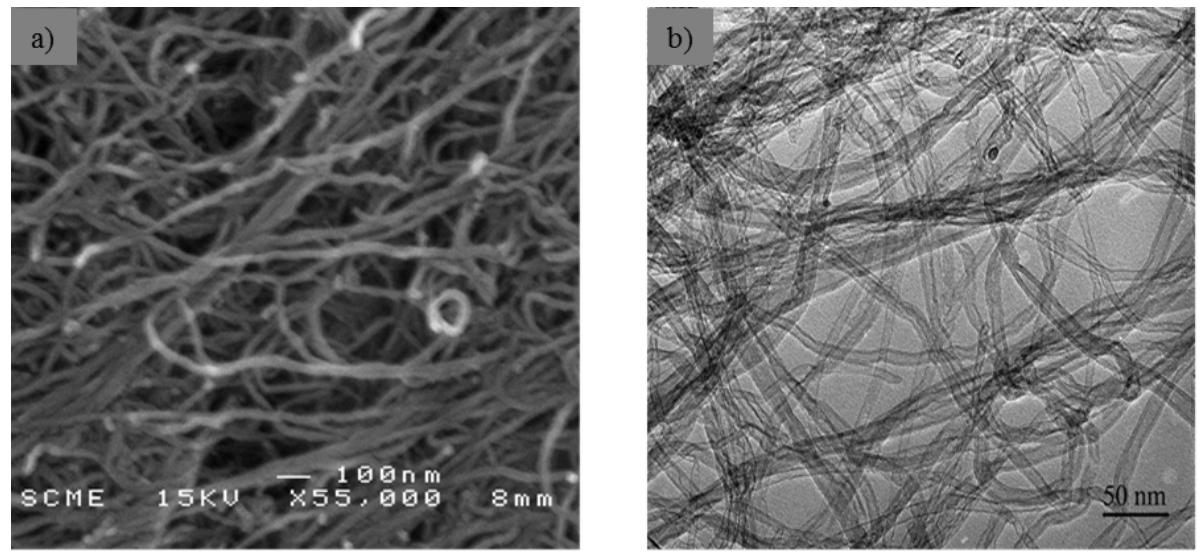

Figure 6. (a) SEM and (b) TEM micrographs of HAD-MWNTs.

After functionalization of MWNT with SPEEK chains, SEM images exhibit a major change in the structure in comparison to pristine MWNTs (Figure 7). The images show that MWNTs are packed in a dense and compact 'bucky paper'-like structure. 

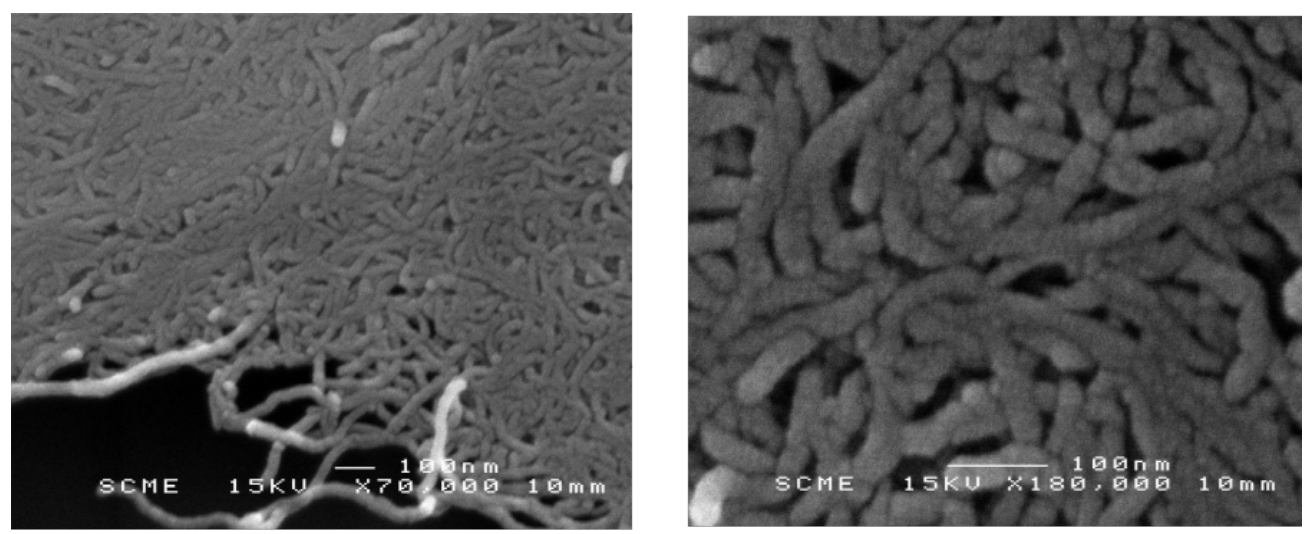

Figure 7. SEM micrographs of SPEEK- MWNTs.

In contrast with the pristine MWNTs, TEM micrographs (Figure 8) of the SPEEK functionalized MWNT show clearly irregular layer of material wrapped around the surface of the nanotubes. One can see that the polymer is attached unevenly on MWNTs surface. Furthermore, no individual tube can be observed despite the long sonication time prior to the TEM observation. The MWNTs are aligned and packed together, forming compact bundle-like structure. The images also illustrate that nanotube bundles are roughly aligned along the axis of the rope in which many tubes are twisted with respect to each other. This structure can be the result of the covalent linkage of SPEEK chains to the nanotubes and the cross-linking of the MWNTs. Indeed, sulfonate groups present on SPEEK-MWNTs surface react with the amine groups present on the surfaces of HDA-MWNTs nanotubes. Hence, SPEEK chains are able to bond directly with many MWNTs and to wrap them leading to the formation of dense CNT network as illustrated in

Fig. 9. Similar morphology was reported in the case of MWNTs functionalization by polymeric amines [22]. A possibility of control of level of packing of such system and its density opens the opportunities to create conductive and functionalized networks of MWNTs and expand potential areas of these promising materials. 

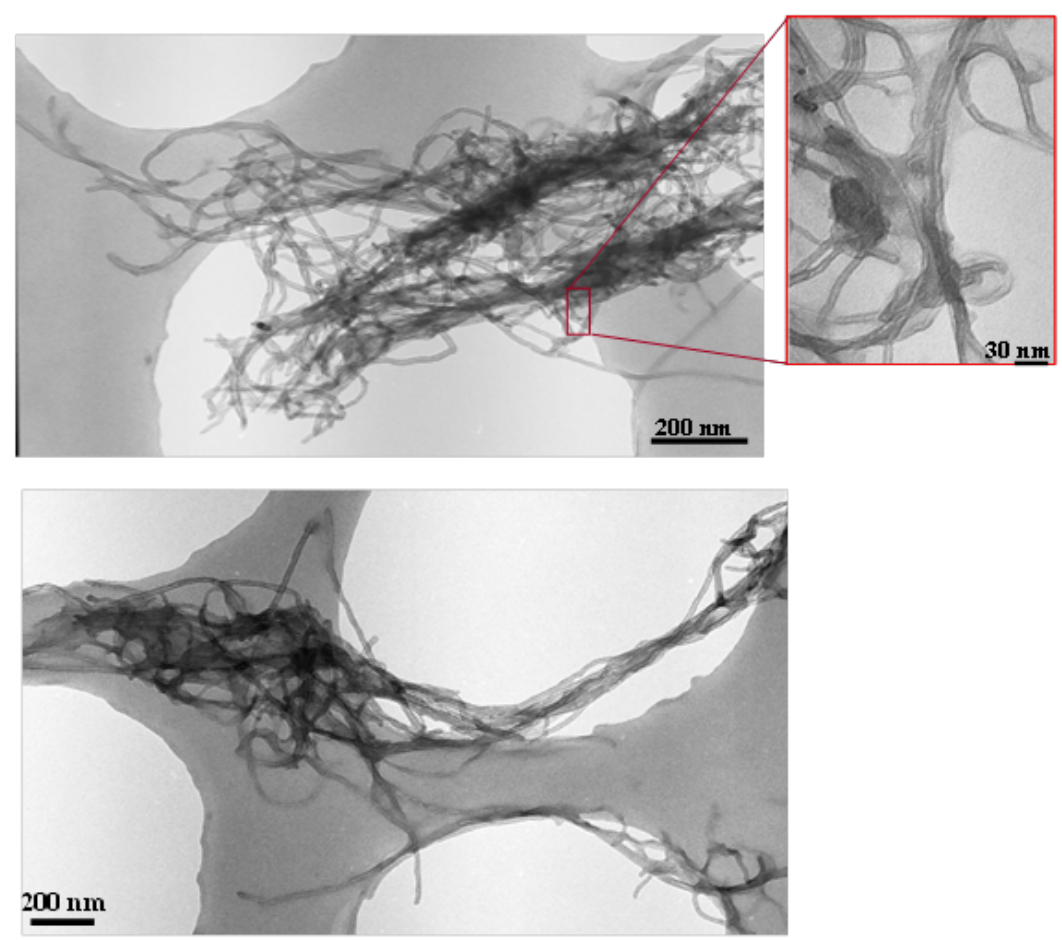

Figure 8. TEM micrographs of SPEEK-MWNTs.

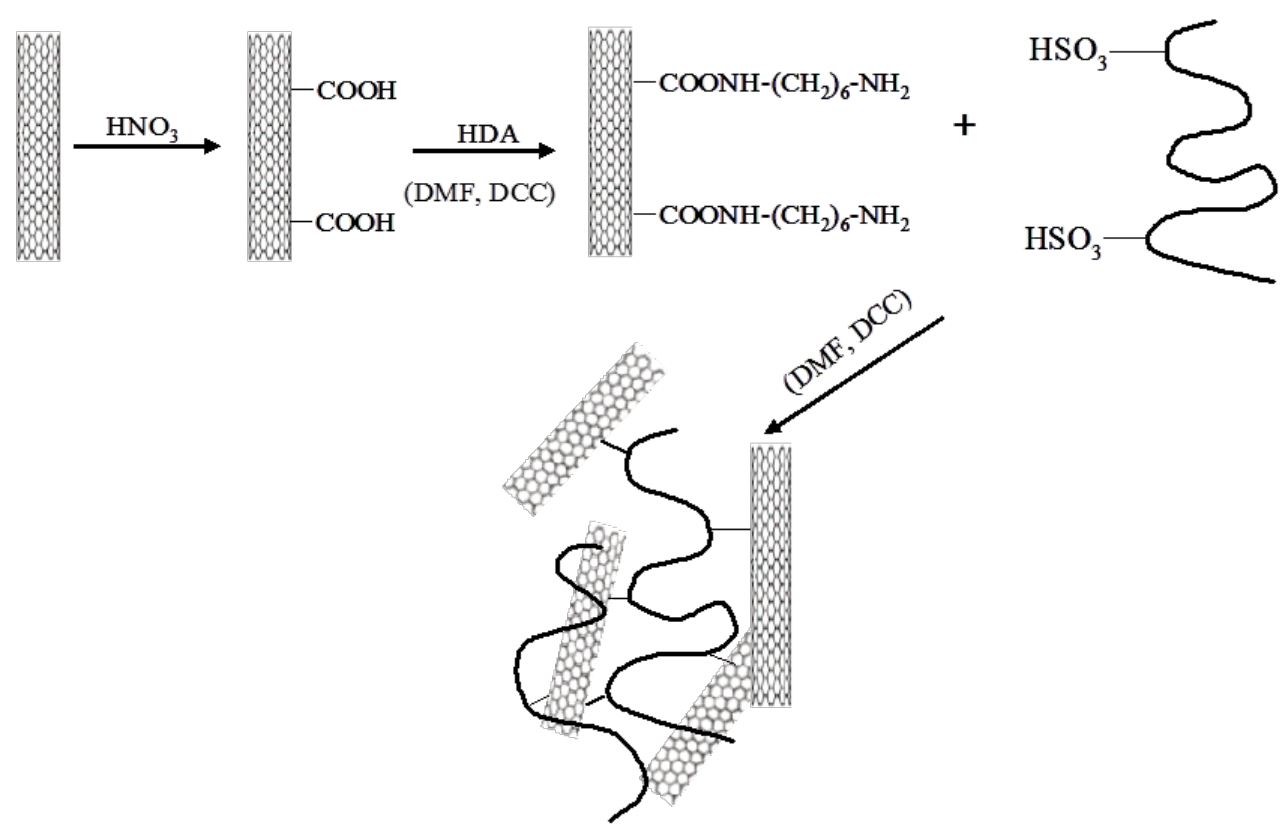

Figure 9. Schematic illustration of MWNTs functionalization of with SPEEK chains. 


\section{Conclusions}

This In conclusion, a functionalization method was successfully applied to graft SPEEK chains on the MWNTs's surface using a bi-functional molecule, namely hexane diamine as a cross-linking agent. FTIR measurements confirm the covalent attachment of SPEEK chains to MWNTs. SEM and TEM observations reveal the aggregation of MWNTs into a highly compact bundle like structure which indicates that nanotubes were connected to each other by the SPEEK chains and a dense network of MWNTs is formed. This result suggest that a simple bifunctional molecule used for covalent crosslinking may not be an efficient way for CNTs functionalization for nanocomposite applications that need a good dispersion of nanotubes in the polymetric matrix.

Author Contributions: Conceptualization, MR.B. and JL.B.; methodology, MR.B.; validation, MR.B. and JL.B.; formal analysis, MR.B. and A.T.; writing-original draft preparation, MR.B. and A.T.; writing-review and editing, MR.B. and A.T.; supervision, MR.B. and Z.B.; project administration, MR.B.; funding acquisition, Z.B. All authors have read and agreed to the published version of the manuscript.

Funding: The authors would like to acknowledge the support of Nazarbayev University research grant \# 284-2019/1012-2019 for this study.

\section{Data Availability Statement}

The data presented in this study are available on request from the corresponding author.

\section{Conflicts of Interest}

The authors declare no conflict of interest.

\section{References}

1. M. M. J. Tracy, T. W. Ebbesen and J. M. Gibson. Exceptionally High Young's Modulus Observed for Individual Carbon Nanotubes. Nature 1996, 381, 678-680.

2. P. Poncharal, Z. L. Wang, D. Ugarte and W. A. de Heer. Electrostatic Deflections and Electromechanical Resonances of Carbon Nanotubes. Science 1999, 283 (5407), 1513-1516.

3. S. J. Tans, A. R. M. Verschueren and C. Dekker, Room-Temperature Transistor Based on a Single Carbon Nanotube. Nature 1998, 393, 49-52.

4. H. Dai, E. W. Wong and C. M. Lieber, Probing Electrical Transport in Nanomaterials: Conductivity of Individual Carbon Nanotubes. Science 1996, 272, 523-526.

5. Amanda S. Wu and Tsu-Wei Chou. Carbon Nanotube Fibers for Advanced Composites. Mater Today 2012, 15, 302-310.

6. P. M. Ajayan, O. Stephan, C. Colliex, D. Trauth. Aligned Carbon Nanotube Arrays Formed by Cutting a Polymer Resin-Nanotube Composite. Science 1994, 265, 1212-1214.

7. S.D. Patil, K. Suresh, F. Ram, M.S Mohan, S.S. Rajput, S. Patil,

P.G. Shukla, K. Shanmuganathan. Functionalized Carbon Nanotube Reinforced Polymer Nanocomposite Microcapsules with Enhanced Stiffness. Colloids Surf A Physicochem Eng Asp 2018, 550, 82-89.

8. A. Bachtold, P. Hadley, T. Nakanishi and C. Dekker. Logic Circuits with Carbon Nanotube Transistors. Science 2001, 294 (5545),1317-1320.

9. V. Georgakilas, K. Kordatos, M. Prato, D. M. Guldi, M. Holzinger and A. Hirsch. Purification of HiPCO carbon nanotubes via organic functionalization. J. Am. Chem. Soc 2002, 124 (48), 760-761.

10. C. A. Dyke and J. M. Tour. Unbundled and Highly Functionalized Carbon Nanotubes from Aqueous Reactions. Nano Letters, 2003, 3 (9), 1215-1218.

11. H. Kong, C. Gao and D. Yan. Controlled Functionalization of Multiwalled Carbon Nanotubes by in Situ Atom Transfer Radical Polymerization. J. Am. Chem. Soc. 2004, 126 (2) 412-413.

12. D. Fong, G. M. Andrews and A. Adronov. Functionalization of polyfluorene-wrapped carbon nanotubes via copper-mediated azide-alkyne cycloaddition. Polym. Chem. 2018, 9, 2873-2879.

13. V. Derycke, S. Auvray, J. Borghetti, C.-L. Chung, R. Lefèvre, A. Lopez-Bezanilla, K. Nguyen, G. Robert, G. Schmidt, C. Anghel, N. Chimot, S. Lyonnais, S. Streiff, S. Campidelli, P. Chenevier, A. Filoramo, M. F. Goffman, 
L. Goux-Capes, S. Latil, X. Blasé, S. Roche, J.-P. Bourgoin. Carbon nanotube chemistry and assembly for electronic devices. C. R. Physique 2009, 10, 330-347.

14. A. Star, Yi Liu, K. Grant, L. Ridvan, J. F. Stoddart, D. W. Steuerman, M. R. Diehl, A. Boukai, and J. R. Heath. Noncovalent side-wall functionalization of single-walled carbon nanotubes. Macromolecules 2003, 36 (3), $553-560$.

15. Anna Maria Díez-Pascual. Chemical Functionalization of Carbon Nanotubes with Polymers: A Brief Overview. Macromol 2021, 1(2), 64-83.

16. H. J. Jeon and J. H. Youk, Synthesis of Water-Soluble Poly(vinyl alcohol)-Grafted Multi-Walled Carbon Nanotubes, Macromol. Res. 18 (5) (2010) 458-462.

17. R. Andrews, M. C. Weisenberger. Carbon Nanotube Polymer Composites, Curr. Opin. Solid State Mater. Sci. 2004, 8, 31-37.

18. J. L. Stevens, A. Y. Huang, H. Peng, I. W. Chiang, V. N. Khabashesku,J. L. Margrave. Sidewall Amino-Functionalization of Single-Walled Carbon Nanotubes through Fluorination and Subsequent Reactions with Terminal Diamines. Nano Lett. 2003, 3, 331-336.

19. L.Yang, J. Chen, X. Wei, B. Liu, Y. Kuang. Ethylene diamine-grafted carbon nanotubes: A promising catalyst support for methanol electro-oxidation. Electrochim. Acta 2007, 53 (2), 777-784.

20. W.F. Chen, J.S. Wu, and P.L. Kuo. Poly(oxyalkylene)diamine-Functionalized Carbon Nanotube/Perfluorosulfonated Polymer Composites: Synthesis, Water State, and Conductivity. Chem. Mater. 2008, 20 (18), 5756-5767.

21. P. W. Chiu, G. S. Duesberg, U. Dettlaff-Weglikowska, and S. Roth. Interconnection of Carbon Nanotubes by Chemical Functionalization. Appl. Phys. Lett. 2002, 80, 3811-3813.

22. Y. Zhang, A. A. Broekhuis, M. C. A. Stuart, T. Fernandez Landaluce, D. Fausti, P. Rudolf and F. Picchioni. Cross-linking of multiwalled carbon nanotubes with polymeric amines. Macromolecules. 2008, 41 (16), 6141-6146.

23. R.Y. M. Huang, P. Shao, C. M. Burns, and X, J. Feng, Sulfonation of poly(ether ether ketone)(PEEK): Kinetic study and characterization. Appl. Polym. Sci. 2001,82, 2651-2660.

24. M.-R. Babaa, J.-L. Bantignies, L. Alvarez, P. Parent, F. Le Normand, M. Gulas, J. Mane Mane, P. Poncharal, and B. Doyle. NEXAFS Study of Multi-Walled Carbon Nanotubes Functionalization with Sulfonated Poly(ether ether ketone) Chains. J. Nanosci. Nanotechnol. 2007, 7, 3463-3467.

25. J-L. Bantignies J-L. Sauvajol, A. Rahmani E. Flahaut. Infrared-active phonons in carbon nanotubes. Phys. Rev. B 2006, 74, 195425-1- 195425-5.

26. B. Vigolo , C. Herold , J. -F. Mareche, J. Ghanbaja , M. Gulas, F. Le Normand, R. Almairac, L. Alvarez, J. -L. Bantignies, A comprehensive scenario for commonly used purification procedures of arc-discharge as-produced single-walled carbon nanotubes. Carbon 2010, 48, 949-963.

27. M. Falk, Infrared Spectra of Perfluorosulfonated Polymer and of Water in Perfluorosulfonated Polymer. ACS Symposium Series 1982, 180 (8), 139-170.

28. R. Naresh Muthu, S.Rajashabala, R.Kannan, Synthesis and characterization of polymer (sulfonated poly-ether-ether-ketone) based nanocomposite (h-boron nitride) membrane for hydrogen storage. Int. J. Hydrog. Energy 2015, 40, 1836-1845.

29. A G. Al Lafi, The Sulfonation of Poly(ether ether ketone) as Investigated by Two-Dimensional FTIR Correlation Spectroscopy. J. Appl. Polym. Sci. 132 (2), 41242 (1- 11).

30. B. Yi, R. Rajagopalan, H. C. Foley, U. J. Kim, X. Liu and P. C. Eklund, Catalytic Polymerization and Facile Grafting of Poly(furfuryl alcohol) to Single-Wall Carbon Nanotube: Preparation of Nanocomposite Carbon. J. Am. Chem. Soc. 2006, 128 (34), 11307-11313.

31. D. Lin-Vien, NB Colthup, WG. Fateley. The handbook of Infrared and Raman Characteristic Frequencies of Organic Molecules, $1^{\text {st }}$ ed.; Academic Press: New York, USA, 1991, PP. 225-250.

32. MR Priera, J Yarwood, ATR-FTIR Spectroscopic Studies of the Structure and Permeability of Sulfonated Poly(Ether Sulfone) Membranes, Part 1. Interfacial water-polymer Interactions. J Chem Soc Faraday Trans 1996, 92, 2731-2735.

33. Y.A. Elabd, E Napadensky. Sulfonation and Characterization of Poly(Styrene-Isobutylene-Styrene) triblock Copolymer at High Ion-Exchange Capacities. Polymer 2004, 45, 3037-3043. 